\title{
Agricultural Heritage Systems Tourism: definition, characteristics and development framework
}

\author{
TIAN Mi1,2 (D http://orcid.org/oooo-0002-7953-558X; e-mail: tianm.13b@igsnrr.ac.cn

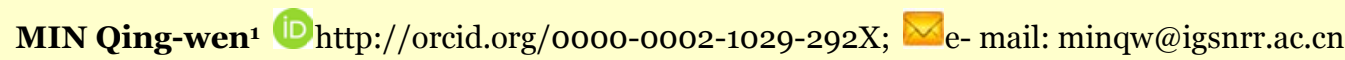 \\ JIAO Wen-jun' (D)http://orcid.org/oooo-0oo1-5458-0440; e-mail: jiaowj1022@163.com \\ YUAN Zheng1 (D http://orcid.org/oooo-0oo2-0271-4125; e-mail: yuanz.11b@igsnrr.ac.cn
}

Anthony M. FULLER',3 (D http://orcid.org/oooo-0003-0513-1870; e-mail: tfuller@uoguelph.ca

YANG Lun ${ }^{1,2}$ (D)http://orcid.org/oooo-ooo1-7284-5377; e-mail:yangl.14b@igsnrr.ac.cn;

ZHANG Yong-xun',2 (D) http://orcid.org/oooo-0oo1-6099-3591; e-mail: zhangy x.14b@igsnrr.ac.cn

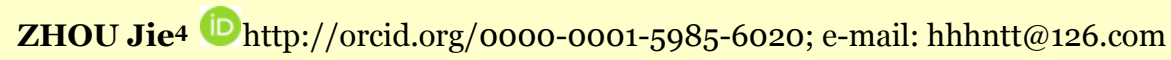

CHENG Bing5 (Dhttp://orcid.org/oooo-0002-7043-6016; e-mail:chengbing@gmail.com

\begin{abstract}
1 Institute of Geographic Sciences and Natural Resources Research, Chinese Academy of Sciences, Beijing 100101, China
2 University of Chinese Academy of Sciences, Beijing 10oo49, China

3 School of Environmental Design and Rural Development, University of Guelph, Guelph, Ontario, N1H2W1, Canada

4Administration of World Heritage in Honghe Hani and Yi Autonomous Prefecture, Mengzi 6611oo, China

5 School of International Education and Exchange, Guilin Tourism University, Guilin 5410oo, China
\end{abstract}

Citation: Tian M, Min QW, Jiao WJ, et al. (2016) Agricultural Heritage Systems Tourism: definition, characteristics and development framework. Journal of Mountain Science 13(3). DOI: 10.1007/s11629-015-3724-2

(C) Science Press and Institute of Mountain Hazards and Environment, CAS and Springer-Verlag Berlin Heidelberg 2016

\begin{abstract}
Agricultural Heritage Systems Tourism (AHST) has increased considerably in the past ten years and is projected to continue growing in the future. Despite such growth, there is not a shared understanding of many aspects of the tourism development framework for all kinds of agricultural heritage sites. Given that meanings and characteristics are critical to determining the appeal of a particular activity among tourism consumers and because the development directions of AHST are essential for achieving heritage conservation goals, a study was conducted in 2014-2015 to assess stakeholder preferences for definitional phrases and their perceptions. This manuscript summarizes the characteristics of AHST in four aspects, taking agri-
\end{abstract}

Received: 24 September 2015

Accepted: 25 January 2016 cultural heritage systems in China as examples: 1) synthesis of agritourism, cultural heritage tourism, and ecotourism; 2) annual variation of tourism attractions and activities; 3) the dominant role of artisan farmers; 4) the unique gastronomic experiences of traditional food. Finally, there are some objectives offered by this research from economic, environmental, cultural, social and political perspectives to build a framework of AHST according to its features and characteristics. Based on environmental and cultural objectives, with political and social support, through reaching the core objectives of economic development, AHST will be sustainable and agricultural heritage systems will be well conserved. This study carries important implications for the further applications of AHST. 
Keywords: Agricultural Heritage Systems Tourism; Tourism perceptions; Tourism characteristics; Development framework; Artisan farmers

\section{Introduction}

In 2005, the designation process of Globally Important Agricultural Heritage Systems (GIAHS) was started by the Food and Agriculture Organization of the United Nations (FAO). Since then, agricultural heritage systems have become world-renowned as resulting from continuous inherited practice over centuries, offering agricultural, ecological, and food services as well as proof that people can live in harmony with nature. As a bio-cultural heritage system of nature-societyeconomy, these ancient systems, which are of unique value in terms of ecology, culture and aesthetics, continue to evolve while retaining evidence of their historical origin (Rössler 2005). Not surprisingly, many have become highly attractive for tourists who can experience rural living and witness ancient ways of agricultural civilization, especially important as a counter-point to modern society's rapid urbanization, growth industries and environmental degradation (Tian et al. 2014).

Agricultural heritage systems are defined as "remarkable land use systems and landscapes which are rich in biological diversity evolving from the co-adaptation of a community with its environment and its needs and aspirations for sustainable development"(FAO 2008). What distinguishes the complexity of the historical character of landscapes is the multiplicity and stratification of footprints left by so many distinct civilizations (Agnoletti 2014). Biodiversity conservation, traditional agriculture, and ecotourism are compatible activities (Eduardo et al. 2007). Tourism development in these areas can be classified as Agricultural Heritage Systems Tourism (AHST). In addition, tourism may provide the basis for dynamic conservation in agricultural heritage systems, as it offers the opportunity for farmers to employ tourism income to keep and enhance the viability of traditional agriculture (FAO 2008; Jansen-Verbeke and Mckercher 2013; Min et al. 2007). The potential of development tourism in agricultural heritage sites which are in peripheral and stagnating areas has been widely recognized by planners, policy makers, non-profit organizations, and academics (Tian et al. 2014; Jansen-Verbeke and Mckercher 2013; Min et al. 2007; Sun et al. 2011; Tang 2012). The value of developing tourism in agricultural heritage sites depends mainly on four identities: settlement attributes, social attributes, economic attributes, as well as ecological attributes (Min et al. 2007). It can be argued that creating responsible linkages between tourism and agriculture shows promise for developing nations, in particular, because a substantial portion of their production and community engagement is intimately linked to agriculture (UNWTO 2009).However, achieving the benefits mentioned above has proven far more difficult in practice than expected (Torres and Momsen 2004; Jansen-Verbeke and Mckercher 2013). Furthermore, in recent years the detrimental or disruptive influence brought by inappropriate tourism has been recognized $(\mathrm{He}$ and Min 2013).

AHST was primarily considered as a method of agricultural economic diversification by agriculturalists, while categorized as a special form of attraction by tourism researchers (JansenVerbeke and Mckercher 2013; Sun et al. 2011; He and Min 2013). Even in tourism research, opinions differed. Jansen-Verbeke concluded that AHST belongs to cultural tourism and its function is to establish the local cultural identity (JansenVerbeke et al. 2008). As one kind of cultural tourism, it not only helps tourists learn more about natural and cultural heritage, but also improves the reflexive means by which local people establish their own cultural consciousness. This definition synthesizes both the supply of tourism resources and tourists' consumer demand, but overlooks the feature of 'nature' and the agricultural identity of AHST; Wang et al. point out that, to a large extent, agricultural heritage systems preservation and ecotourism share similar aims such as benefiting the locals while conserving the ecosystem, so that AHST can be treated as synthetic ecotourism (Wang et al. 2006). This statement focuses on the cultural and eco-impacts of tourism activities. However, the relationship of traditional agriculture and tourism development is lacking. Without emphasizing its heritage property, Vafadari claims that traditional agriculture can help create a 
market for rural tourism (Vafadari 2012).

Rural tourism has developed in many parts of the world, especially in less developed countries, and has substantially expanded since the 1970s, and can provide abundant experiences for AHST (Lane 2009; Long et al. 2000). Agricultural Heritage Systems Tourism strengthens the experiences of the whole agricultural system by integrating nature with culture (Tang 2012), a return to the origins and the "authentic", therefore it can be treated as the essential pattern of rural tourism as its premium and diversified resources. Nevertheless, the research on AHST and its many definitions are not sufficient, and a satisfactory concept of AHST has not yet been established.

Tourism academics have concentrated mainly on the role of locals in agricultural heritage systems conservation and tourism development at this stage. Agricultural heritage system is the typical community heritage, so that it is essential for tourism development and heritage preservation to clarify the perceptions and attitudes of locals. When rural areas are the context of heritage tourism, effort is needed to establish linkages between tourism and the local economy by addressing the following issues: lack of skilled human resources, capital, access to credit, and other assistance; preventing leakages and reducing the dominance of urban players (Kausar 2010). Hjalager introduces measures to improve interorganizational set-ups if rural tourism is to be launched on any large scale (Hjalager 1996). Proposals in the literature include recognizing the residents' rights of heritage, developing environmental protection regulations and encouraging residents to participate in tourism development decision-making (Tang et al. 2010). In Japan, to increase incomes of rural households by developing green tourism in a GIAHS project, the Shunran-no-Sato group, which is an organization of farmers in the Noto Peninsula, has been set up (Chen and Qiu 2013). Lessons from Southern Öland in Sweden show that trust, communication and local influence are vital ingredients in a participatory approach (Marie 2009). A location-based conceptual framework of agricultural heritage systems preservation in partnership with tourism development at a community scale is put forward in agricultural heritage sites by Sun et al. (2009, 2013a, 2013b).
Besides community involvement, other characteristics of AHST should be exploited, so that a considerable comprehensive development framework can be established based on its common features.

In conclusion, until recently, AHST has not been explored systematically in terms of either its benefits or possible detriments. First, the lack of clarity and shared understanding of AHST jeopardizes the creation of policies which are needed for economic development to help increase farm incomes in traditional farming areas. Also hindered is the development of marketing strategies (Veeck 2006), which in turn diminishes efforts to offer more access to the public. From an academic perspective, a clear understanding of any phenomenon is necessary to determine its characteristics (Phillip et al. 2010); Second, traditional agriculture is one of the oldest and most fundamental parts of the local economy, whereas tourism is one of the newest and most promising. The synergy between traditional agriculture and tourism should be researched in-depth. Last but not least, it is imperative to build up complete frameworks for AHST according to the nature of its tourism resources, for guiding both traditional agriculture and tourism development in a sustainable way, and finally realizing the aims of agricultural heritage systems conservation.

In response to these challenges, studies were undertaken in 2014 and 2015 at agricultural heritage sites in China to reveal understandings of AHST from five stakeholder groups: farmers, tourists, governments, tourism companies, and related organizations. According to these responses on different preferences of stakeholders, characteristics of AHST were summarized to clarify the differences from other types of tourism activities, which can be considered as detailed annotations to the concept. Pointing to the common ideas about AHST and its characters, a systematic development framework should be offered for the whole picture, including economic, environmental, cultural, social and political objectives. The system constructed to promote tourism in agricultural heritage sites addresses the main conflicts and enhancement assets, and then realizes heritage conservation finally by involving every stakeholder's view, endeavor and commitment. 


\section{Methodology}

The importance of depth and detail, in terms of exploring participants' understanding of AHST, underpinned the selection of a qualitative approach in this research. Semi-structured interviews were chosen as it is convenient to collect "detailed, information rich and extensive" data that can be used to understand social practices (Snape and Spencer 2003), such as AHST. Five sample groups, which are the key stakeholders of AHST, were targeted in this study in 2014 and 2015 in agricultural heritage sites in China such as the Honghe Hani Rice Terraces System in Yunnan province and Qingtian Rice-Fish System in Zhejiang province. Selected were local community respondents $(n=28)$, tourists ( $n=194)$, personnel in tourism companies $(n=20)$, government officials $(n=20)$, and experts from heritage conservation organizations $(n=10)$. All of them are indispensable parts of the AHST (Figure 1).

These respondents were asked the same basic questions: to explain what they understood about the meaning of AHST, which allowed them to describe their perceptions of AHST in an open, uninfluenced way. More specific information for each group was solicited as follows: (1) tourists were questioned about their travel aims and preferences in this special tourism destination and their communications with the locals; (2)the farmer locals were asked about their participation in AHST such as receiving visitors and producing souvenirs and if they benefit from these kind of activities, as well as about how tourism affects their traditional agriculture; (3) a survey of tourism companies concerned the situation of locals involved in tourism job opportunities and how the benefits were shared, especially the tourism activities designed to connect and promote traditional agriculture in a sustainable way; (4) experts from organizations of heritage conservation were consulted about the relationship between nature, culture preservation, and tourism development; (5) government officials were asked about the policies and rules to support AHST without over-development, and how to protect local farmers' rights and to maintain their farming traditions.

Subsequently, different groups of responses were analyzed by Content Analysis to identify their categorization according to AHST. Content Analysis can examine any text or content of communication which can be turned to text, with objective, systematic, quantitative, descriptive and distinctive characteristics (Singletary 1993). The highest frequency of indicators from the five groups was observed to compare and identify the essential ones. This study took an interpretivist perspective that it is possible to find a common theme within multiple individual interpretations of AHST, though the concept of AHST is understood and defined subjectively by individual actors. Based on the definition they offered, respondents were prompted for their perceptions in relation to the themes mentioned above. Systematic thematic analysis of interview transcripts was conducted using the "Framework" approach (Ritchie et al. 2003), assisted by NVivo 10 (qualitative data analysis software). The specific analysis process was formulated as in Table 1.

After identification, the indicators were tested by agreement values to show if the result is reliable. Evaluation analysis was usually used in this step, that is, to test the degrees of credibility by comparing the reliability percentage. If the overall measurement of agreement for indicators in definitions reaches to $80 \%$ or surpasses this level, the results are considered to be acceptable ( $\mathrm{Lu}$ et al.

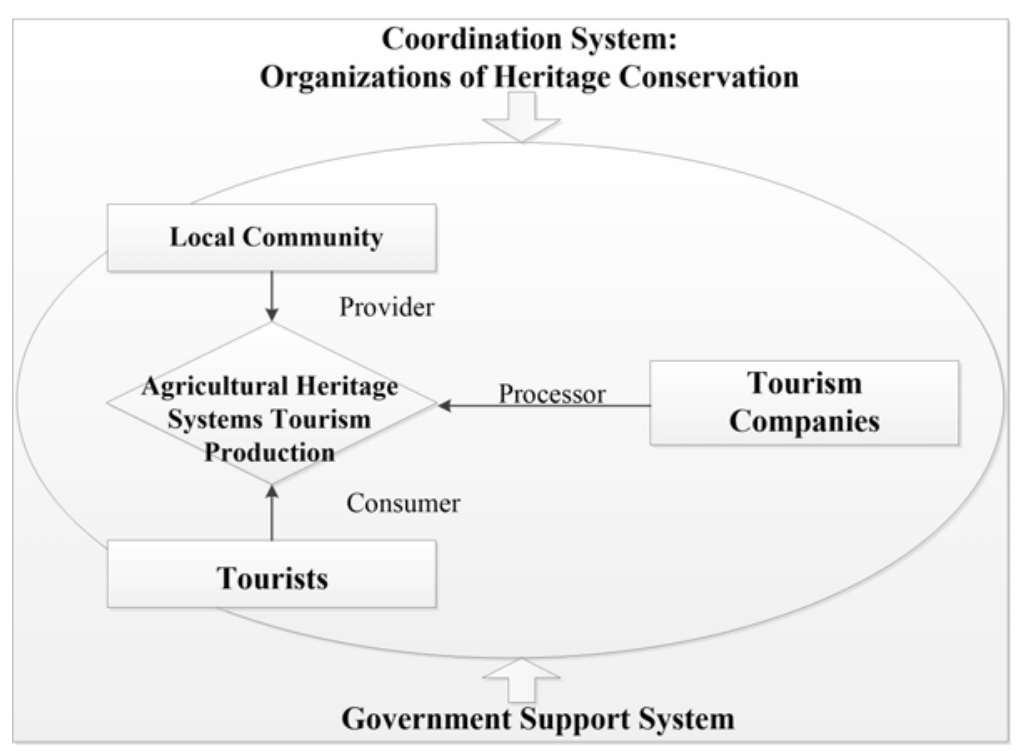

Figure 1 Stakeholders in Agricultural Heritage Systems Tourism. 
Table 1 Analysis process of definition about Agricultural Heritage Systems Tourism based on Content Analysis

\begin{tabular}{l|l}
$\begin{array}{l}\text { Research } \\
\text { object }\end{array}$ & $\begin{array}{l}\text { Find out the common definition of } \\
\text { AHST }\end{array}$ \\
$\begin{array}{l}\text { Data and } \\
\text { information }\end{array}$ & $\begin{array}{l}\text { Main terminology and analysis units of } \\
\text { definition }\end{array}$ \\
$\begin{array}{l}\text { Type of data } \\
\text { and } \\
\text { information }\end{array}$ & $\begin{array}{l}\text { Identification of qualitative indicators, } \\
\text { classification, frequency statistics and } \\
\text { sorting the indicators }\end{array}$ \\
\hline $\begin{array}{l}\text { Resource of } \\
\text { data and } \\
\text { information }\end{array}$ & Representative and authoritative \\
\hline $\begin{array}{l}\text { Analysis of } \\
\text { data and } \\
\text { information }\end{array}$ & $\begin{array}{l}\text { Thematic analysis, classification, } \\
\text { frequency statistics, sorting, } \\
\text { comparison of the concordance }\end{array}$ \\
\hline $\begin{array}{l}\text { Statistical } \\
\text { description }\end{array}$ & $\begin{array}{l}\text { Describing statistics of the indicators } \\
\text { identified from definitions of AHST by } \\
\text { interviewees. }\end{array}$ \\
\hline $\begin{array}{l}\text { Research } \\
\text { Results }\end{array}$ & $\begin{array}{l}\text { Obtain the key indicators of AHST and } \\
\text { define its concept }\end{array}$ \\
\hline
\end{tabular}

Table 2 The analysis of Agricultural Heritage Systems Tourism indicator frequency

\begin{tabular}{|l|l|l|l|}
\hline Order & Indicators & Freq. & Rate \\
\hline 1 & $\begin{array}{l}\text { Benefit local community } \\
\text { Educate the visitors/public about } \\
\text { traditional agriculture }\end{array}$ & 37 & $74 \%$ \\
\hline 3 & $\begin{array}{l}\text { An attractive natural environment } \\
\text { and agriculture setting }\end{array}$ & 32 & $68 \%$ \\
\hline 4 & $\begin{array}{l}\text { Attracted by traditional rural } \\
\text { culture }\end{array}$ & 31 & $62 \%$ \\
\hline 5 & Participate and experience & 29 & $58 \%$ \\
\hline 6 & $\begin{array}{l}\text { Attracted by traditional agriculture } \\
\text { practices }\end{array}$ & 28 & $56 \%$ \\
\hline 7 & Recreation & 28 & $56 \%$ \\
\hline 8 & $\begin{array}{l}\text { Share agricultural heritage with } \\
\text { visitors }\end{array}$ & 26 & $52 \%$ \\
\hline 9 & Local flavor food & 25 & $50 \%$ \\
\hline 10 & Photograph opportunities & 19 & $38 \%$ \\
\hline 11 & Agriculture product shopping & 15 & $30 \%$ \\
\hline 12 & $\begin{array}{l}\text { A connection between agriculture } \\
\text { and tourism }\end{array}$ & 12 & $24 \%$ \\
\hline 13 & Close to nature & 8 & $16 \%$ \\
\hline 14 & $\begin{array}{l}\text { Evoke visitor's nostalgic feeling } \\
\text { Exercise and fitness }\end{array}$ & 6 & $12 \%$ \\
\hline 15 & E & 5 & $10 \%$ \\
\hline
\end{tabular}

Note: Freq. $=$ Frequency

2006; Ryan and Bernard 2000).

\section{Results and Discussion}

\subsection{The definition of Agricultural Heritage Systems Tourism}

Extracting the key words from respondent definitions, there are 15 indicators. The credibility of three coders is 0.917 , which shows a very high consistency in the contents and far surpasses the basic standard of o.8. After calculation, the key indicator frequencies and rates of presenting to the whole were derived (Table 2).

From Table 2, we can see that the frequencies of indicators identified from samples are quite different, in which some indicators are up to more than $70 \%$, but some others only to $10 \%$. The results show different stakeholders have diversified understandings of AHST. Therefore it becomes necessary to formulate a common concept accepted by all stakeholder groups. A universally accepted and consistent idea about AHST can make clear guidelines for further developing those areas with precious and particular tourism resources. In addition, meanings are critical to determine the appeal of a particular activity among consumers (Gilbert 1990). To do so, words were identified that at least one-half $(50 \%)$ of the stakeholders considered should be included in a good definition of AHST.

There is a lot in common among the indicators. Nine indicators occure more than 50\%:"benefit local community", "educate the visitors/public about traditional agriculture", "an attractive natural environment and agriculture setting", "attracted by traditional rural culture", "participate and experience", "attracted by traditional agriculture practices", "recreation", "share agricultural heritage with visitors", and "local flavor food". Although, the frequency of "photograph opportunities" and "agriculture product shopping" are relatively high in the visitors group and some local tourism companies, it was far lower than $50 \%$ in total. Thus these indicators haven't been treated as a commonality of different understandings and shouldn't be included in the definition.

A major point of disagreement that arose in the investigation related to ideas about AHST held by different stakeholders, specifically related to "Educate the visitors/public about traditional agriculture". Results showed that the education function of AHST is a recurrent element across the majority of respondents in each sample (80\%), although a smaller proportion among visitors (20\%). Therefore, education activities should be considered as a key part of the definition. Meanwhile, the huge difference also points out a further task in developing AHST, such as, the 
heritage value and its education function should be promoted more.

In view of those preferences, study results suggest that an integrated definition of AHST could be: "Attracted by traditional agriculture practices, flavorful food and associated rural culture, visitors have experiences in an agricultural heritage setting within an attractive natural environment, for educational and recreational purposes. As a result, local communities should benefit from sharing their heritage with visitors."

\subsection{Characteristics of Agricultural Heritage Systems Tourism resources}

Agricultural heritage systems have both natural and cultural properties, and result from a long history of industrious and rational human labor in a harmonious relationship with nature. A myriad of labels (e.g, rural tourism, agritourism, natural and cultural heritage tourism, ecotourism, leisure or recreational agriculture) are used in tourism development of agricultural heritage sites to depict this form of experience. Lack of a clear definition is constraining marketing and appropriate development. None of these labels can adequately describe AHST in a comprehensive and accessible way.

\subsubsection{Synthesis of agritourism, cultural heritage tourism and ecotourism}

Agricultural heritage systems are remarkable demonstrations of human ecological knowledge and creativity, the sustainable coexistence of humankind and nature, with the potential to increase land productivity and enhance biodiversity. Based on natural resources, agricultural heritage systems can be divided into two parts: agriculture activity and folk culture (Figure 2). The traditional agriculture system has created spectacular landscapes and wise cultivation knowledge about land and water utilization in agrarian practices, as well as distinctive agriculture production. Thus it can be seen that agritourism will develop well in sites that have well-protected natural surroundings including soil, water, and air, as well as ecological systems consisting of all kinds of biological communities, which are rarely disturbed, in a specific area which is suitable for balancing eco-tourism activities. Deriving from agriculture production, an integrated culture system has been built and passed down from generation to generation in the heritage area. The valuable cultural heritage represents the unique characteristics closely related to the local history and culture; visitors are attracted to experience these characteristics in various ways. In conclusion, AHST sites have combined the properties of agritourism, ecotourism, and cultural heritage tourism at any one location.

AHST can be treated as a more specific subset and a quintessential part of agritourism because of its heritage value. In particular, the essential aim of developing tourism around agricultural heritage is to preserve and sustain traditional agriculture, not just cater to society's curiosity and improve the local economy, which are the basic objectives of agritourism. It is imperative to make a fair and sustainable use of agricultural multi-functions to ensure their mutual support in the realization of integral regional development and the conservation

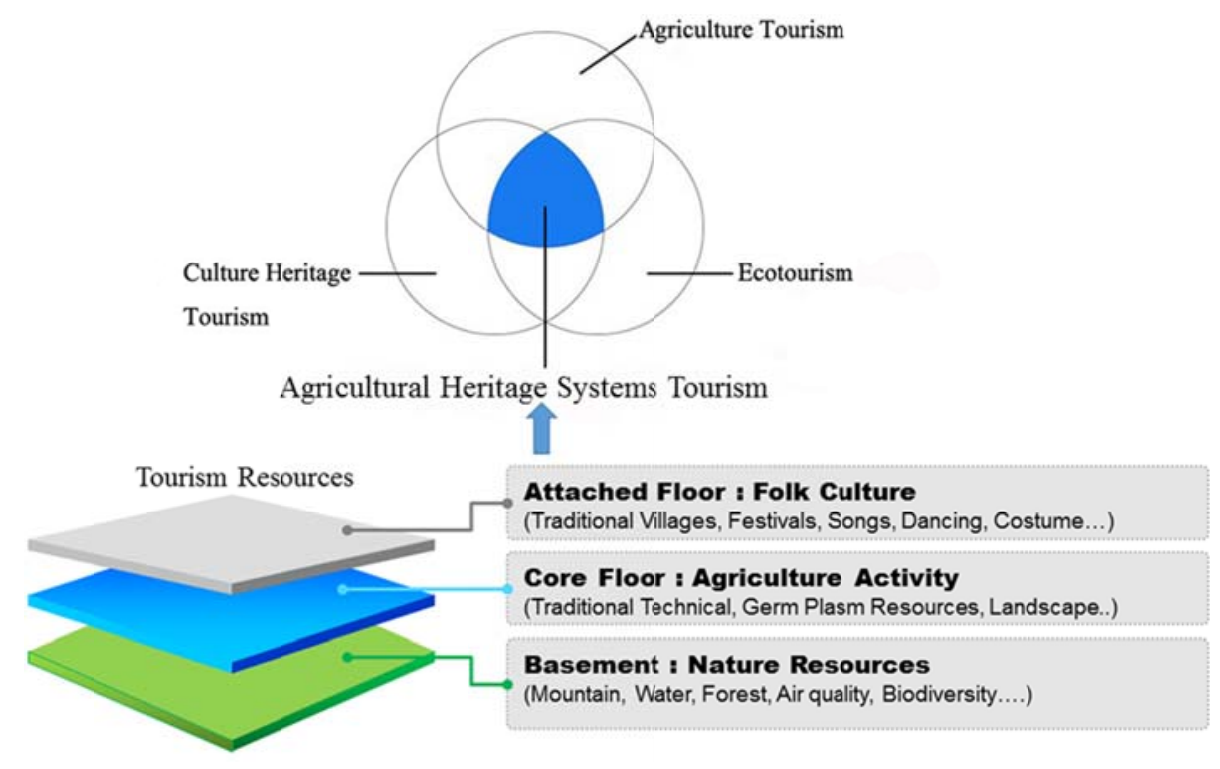

Figure 2 Tourism resources in Agricultural Heritage Systems Tourism. 
of traditional agriculture. The essential objective is one of sustainability. In the Hani terraces area, as the magnificent terraced landscape has begun to attract increasing numbers of tourists in the past ten years, some of the locals have begun to abandon farming the rice terraces in favor of livelihood opportunities in the tourism industry. Considering the great value of the terraces for food security, ecological functions, and environmental protection, it is essential to conserve traditional farming, and tourism should not be in conflict with agriculture development, but an integral part of it, as in agritourism. Only when traditional agriculture is sustainable can the tourism resources in these places be ensured.

Agricultural heritage areas have ecological vulnerability as they sustain a balanced ecological system in semi-closed spaces. Clearly, tourism activity is one of the human disturbances in a finally balanced system. For example, in the Hani terraces, the villages are built on the mountainsides; above the villages are the flourishing forests and the terraces are just below the village. Water in the system runs by gravity in trenches to form a circle which supports forests-villages-terraces-riverclouds-forests. As the number of visitors to the Hani terraces continues to increase, many new family hotels are built and managed in the villages. Therefore large volumes of water have been appropriated for satisfying the demands of tourists and less water runs into the terraces, which leads to a shortage of irrigation water. In addition, a new sewage disposal problem has arisen. From this we can conclude that an ecotourism model which is environmentally-friendly is especially necessary in these areas.

AHST also has the property of cultural heritage tourism which is a kind of higher level of spiritual and cultural activity. Cultural heritage is living historic continuity. During agricultural activities, people have their special cultural traditions involving faith and religion, festivals, arts and knowledge, as well as their personalities. These reveal the cultural identities of local people, which are also vulnerable. Inappropriate tourism development will bring social and cultural conflict (Pe'rez and Nadal 2005). Thus, tourism development in cultural heritage sites should respect local ways and beliefs and minimize acculturation from tourism. For example, since ancient times, the indigenous Hani worship their land, forest and nature devoutly. They have a complete system of sacrifices with some taboos; when one is broken, disasters follow. Also in the Qingtian rice-fish culture system, at the time of tasting new rice, farmers will offer cooked fish from the paddy fields as a sacrifice to their ancestors and the Gods of Heaven and Earth. AHST tourist experiences can feel the charm of authentic culture, and are motivated to learn about traditional cultures in advance of visiting in order to prevent disturbances to the system. In the end, the question is about scale-the carrying capacity- of heritage sites to cope effectively with tourists as well as maintain their traditional practices and community lives.

\subsubsection{Annual variations of tourism attractions and activities}

The core resource of AHST is the agriculture production system, which means the biological reproduction processes and interaction with the system that acts to regulate human intervention. AHST is different from tourism in historic sites, urban scenery tours, miniature landscapes or natural and cultural heritage. The tourism activities, such as agricultural landscape sightseeing, witnessing the farm practices and eating local food are all closely linked with the reality of village agricultural production. Therefore, AHST has many seasonal characteristics because of the time sequence of agricultural activities.

Folk cultures of the local community in an agricultural heritage systems are all based on agricultural activities which are also cultural entities. The cultural system, encompassing tangible cultural heritages including the villages, dwellings and buildings for production, the sacred woods of the villages, irrigation works and road signs etc. and intangible cultural heritages such as the traditional rice production and life styles, traditional customs and festivals and knowledge systems passed down orally, etc., derive from agriculture cultivation procedures, that also vary with time and ecological meaning. Thus, AHST productions are diversified and change over time in a year according to different resources and changing circumstances. These characteristics remind us that tourism development in agricultural heritage systems can be sensitively designed 
according to the variations in the agricultural cycle and avoid low-peak season problems.

Just as the terraced landscapes change throughout the year, the festivals of the Hani minority are celebrated in different seasons and are devoted to acknowledging the achievements in a farming year. At the same time, festivals are closely linked to ceremonies and the blessing of agricultural activities with prayers (Figure 3). These festivities account for a large part of the agricultural heritage of the people and have become attractors for a variety of tourism activities. Participatory experiences in agricultural activities and the lives of farm people improve the quality of tourism; tourists are not only sightseeing the landscapes for photographs, but are also learning more about the ingenious meanings of the agricultural heritage systems.

\subsubsection{Artisan farmers play a dominant role}

Artisan farmers are those who use traditional, small-scale, sustainable farming techniques to produce the finest food products possible and reconnect consumers with agricultural heritage systems. Without mechanization, they work in the terraces using simple technology, traditional knowledge and their own skill. Artisan farmers are of vital importance in AHST because all of the tourism resources at the site are supplied by the farmers and their families. Their families have sustained the agricultural heritage systems for a long time, from generation to generation, and continue the traditions. Additionally, they are also exhibitors and successors of the historical culture, the producers and sellers of tourism commodities which are mainly agriculture produce, as well as the hosts to welcome visitors from the outside world and show them around.

Given the non-fungible position of local artisan farmers, they should be the principal beneficiaries in tourism development in agricultural heritage - not only the locals who directly participate in tourism offering accommodations and restaurants, but also the farmers. Because of low energy consumption, no pollution and intensive cultivation, traditional agriculture needs plenty of laborers to invest in the heavy workload. Produce from traditional agriculture has high ecological value, but yields are considerably lower than in modern agriculture. In recent years, young people have left to work in cities to earn better incomes for their families. Without farmers working in the terraced fields, the agricultural heritage systems can't be preserved. Neither can tourism develop in a sustainable way. On the other hand, the income gap between people who manage tourism services and peasants will cause shocks for local community and traditional
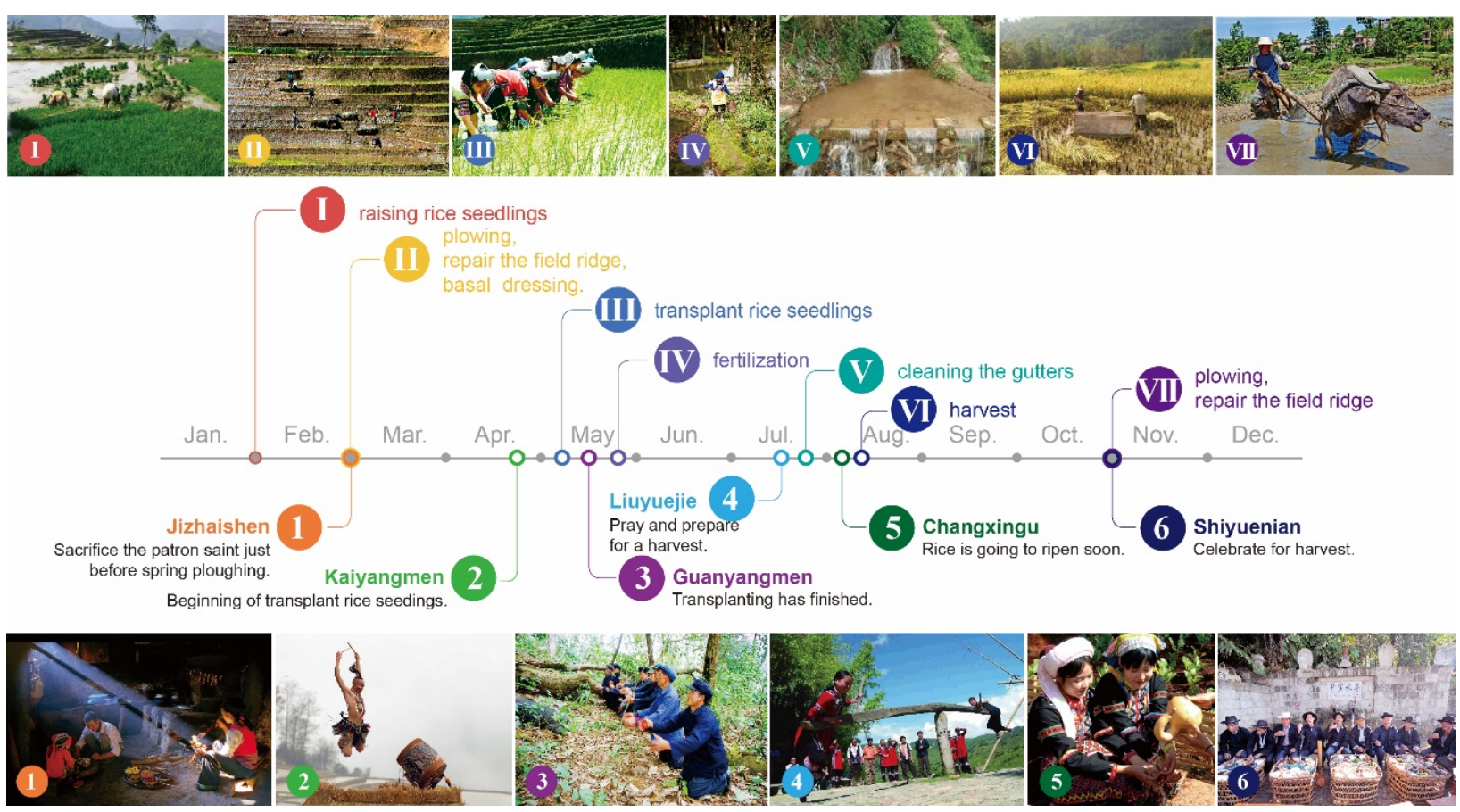

Figure 3 Festivals and agricultural activities in Hani terraces (Tian et al. 2015). 
culture. Thus, a subsidy from tourism should be given to the locals, especially those who are willing to persist with agricultural activities, but can't benefit from tourism directly.

The Hani rice terraces, formed by more than a thousand years of uninterrupted farm labor, are world-famous because of their broad scale, which reaches 1 million $\mathrm{mu}(1 \mathrm{mu}=0.0667$ hectares) along the entire bank of the Hong River. Land reclamation and cultivation in the terraces are especially difficult (Figure 4). By virtue of their extraordinary industry and intelligence, Hani people have created this great agricultural heritage system, which is also precious as a tourism resource. As well as in Qingtian, the farmers take care of rice and fish like their own babies, which forms a picture of pastoral scenes with fish leaping out of water in the rice fields.Thus, as the provider of this resource, artisan farmers should reap the main benefit from tourism and exercise their rights to prosper.

\subsubsection{Special gastronomic experiences of traditional food}

Agriculture provides not only the background for attractions in rural environments, but also the tourism industry resources for food consumption (Telfer and Wall 1996). The linkages between tourism and traditional agriculture contribute to the ethos of sustainable tourism. The growth in consumer demand on a global scale for healthy food is driving opportunities for rural tourism initiatives and stimulating tourism industry demand for local food production. Also, food and beverage consumption represents a significant part of tourist expenditure. In these places, "local food" has the potential to enhance the visitor experience by connecting consumers to the region and its perceived culture and heritage (Sim 2009). For satisfying the increasing desire of tourists for "authentic" experiences, locally produced foods and food products, which support traditional agricultural production in heritage sites, can be an integral tool for sustainable tourism. Especially for agricultural heritage sites which are usually located in remote areas with difficult access, tourism allows farmers to reduce food miles by bringing the market to the farmers and so cutting the costs of transporting food and producing food waste.

Food products that are perceived to be traditional and local and the development of "alternative" food networks appeal to visitors who increasingly demand food authenticity from heritage sites (Sim 2009). The Hani terrace rice agricultural heritage system supplies rich food experiences all year long and visitors can taste featured food produced on a seasonal basis. During the period of rice growth, local people put fry and ducklings into the terrace to breed. They can get fish and duck (eggs) when harvest time arrives; in the slack season, aquatic animals (such as snails, eel, and mud fish) and plants (such as water arum and lotus root) can be found in the rice fields and cooked; there are also vegetables planted in the terrace margins.

Food festivals and the marketing of specialist products are seen as a salient part of AHST. Production sites that are usually in the core area of
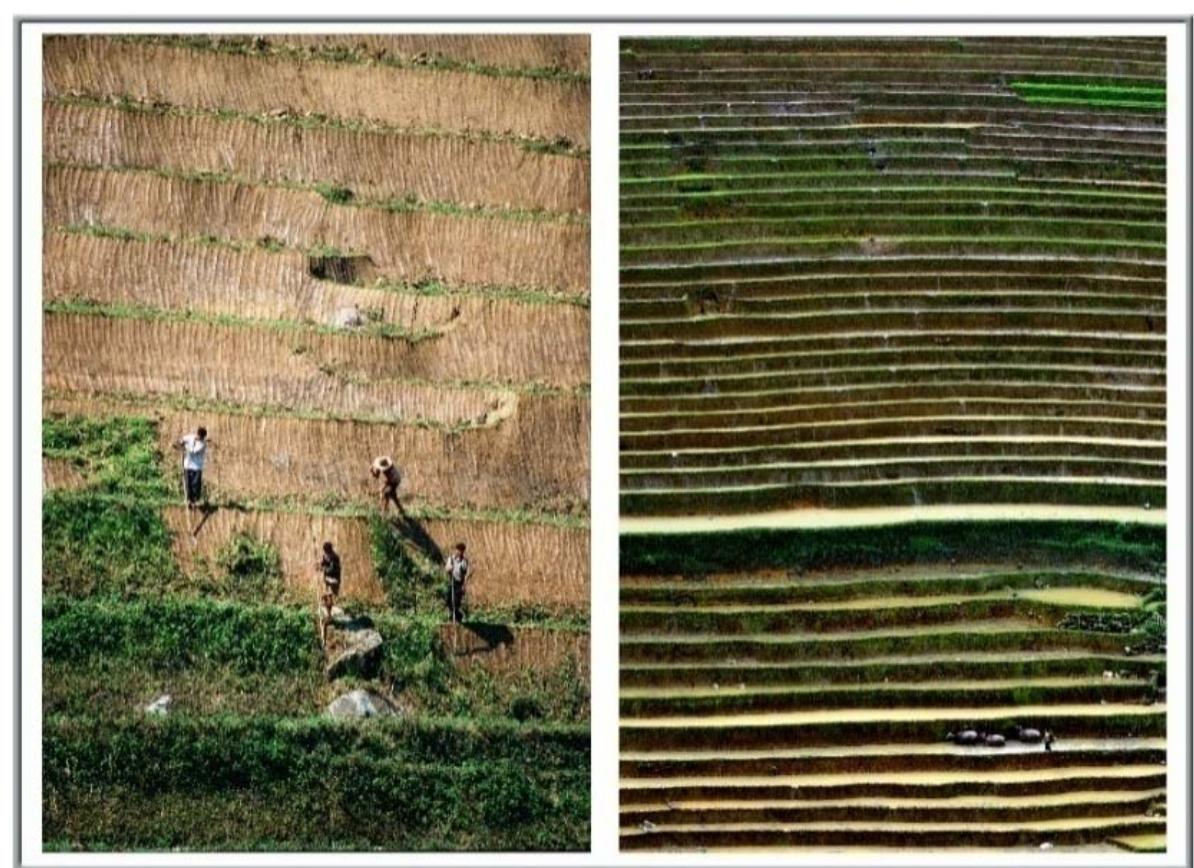

Figure 4 Artisan farmers are building Hani terraces. 
agricultural heritage systems have become important tourist attractions such as field fish in Qingtian (a local carp species), which is famous for its tender meat and rich nutrients. Besides that, the superior eco-rice is also an improved variety with a plump grain and a pure taste. According to the investigation, nearly $96 \%$ of the tourists come to Longxian village (core area of the rice-fish culture system) for fish dinner. Especially during culinary festivals, folk arts such as the fish lantern dance further enrich the cultural system. Indeed, local foods may be particularly popular with tourists because they are considered "iconic" products that capture the "typical" nature of a particular place (Bessière $J$ 1998).

\subsection{Development framework of Agricultural Heritage Systems Tourism}

Goals are important in tourism planning and development for providing broad directions and making it clear that some aims are more important than others. Hence, the establishment of priorities is important in any definitional system (Saveriades 2000).Tourism is a common way to conserve agricultural heritage systems because of its dynamic potential to adapt. According to the characteristics of tourism resources in most agricultural heritage sites, the production system has been made to lend itself to agro-sightseeing tours, science research and education tourism, gastronomic experiences, natural environment leisure, and ecological and folklore cultural experiences. To reach the final goals of heritage preservation and sustainable tourism development in these sites, the pressing issue is that artisan farmers can benefit enough to remain in farming and that the local community can participate effectively, as only they can maintain traditional agriculture as a living system. There are some objectives offered by this research from economic, environmental, cultural, social and political aspects to build a (AHST). framework of AHST according to these characteristics. Based on environmental and cultural objectives, with political and social supports, through reaching the core economic goals, AHST will be sustainable and agricultural heritage will be well conserved as a dynamic system (Figure 5).

\subsubsection{Economic objectives}

The local community should be the principal recipient of core benefits from tourism development, receiving sustainable income in order to maintain their commitment and lifestyle. Benefit sharing is one of the surest ways to demonstrate that such sites are managed along sustainable lines. There are some measures for establishing a mechanism for the reasonable distribution of interests and for realizing the improvement of residents' living standards.

(a) Offering job opportunities for local residents. The government and tourism companies should give preference to local residents for jobs such as infrastructure construction, management of scenic areas, accommodation and restaurants. Some tourism projects should retain a certain share for locals, even letting them operate facilities and services as first choice.

(b) Encouraging and guiding the residents who have relative ability to work in the tourism business and benefit from it directly under the premise of property privatization and well defined power and responsibility. The government should offer some preferential terms to the people who supply special services that tourism companies can't; for example, a family inn, local snacks, farming experiences and especially agriculture production and food sales as

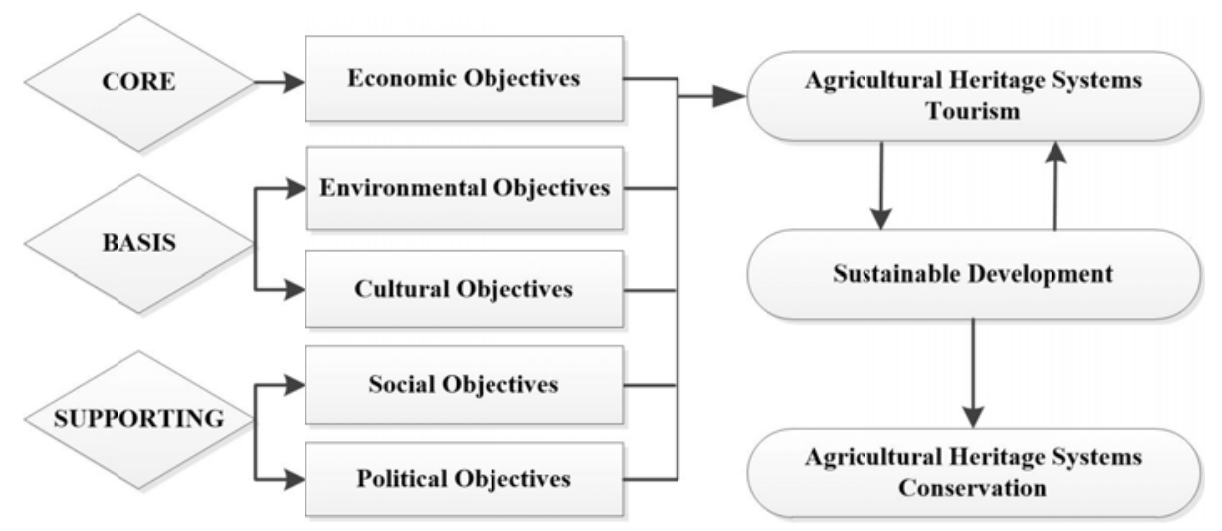

Figure 5 The development framework of Agricultural Heritage Systems Tourism 
tourism commodities. All these commodities are supposed to use local materials and be made in native places and among them, distinctive agriculture products ought to be the most competitive ones. The government should also encourage family-style production, support the construction of a community goods production base and encourage small-scale processing zones.

(c) Coordinating the relationship among the locals and maintaining fairness of distribution of interests. Nearly all of the farmers in heritage sites are contributors to landscape, culture and environmental maintenance, although they may not run tourism services directly. There should be some ways, such as collective funds compensation or second distribution of interests, to ensure their rights.

(d) Building up the allocation mechanism based on a shareholding system. Shareholding systems can enable all stakeholders to participate in tourism development through assessing the heritage resources and asserts such as land, facilities, traditional agriculture technology and folk culture and so on into equity stakes. The locals can take a stake with labor and capital in scenic area development and auxiliary projects.

\subsubsection{Cultural objectives}

The main cultural objectives include two aspects: local individuals realize and are proud of heritage values, feel confidence in their survival abilities, and join heritage conservation willingly; the visitors can know about the impact they may have on the local culture, learn about traditional agricultural resources and knowledge,and respect it. To the locals, objectives should be achieved mainly through different levels and classes of education and training activities. Education about the heritage value of their system and possible results of tourism development allows locals to make their own choices about the ways to choose tourism and development directions. For the tourists, there should be a greater variety of creative tourism ventures that offer opportunities for in-depth experiences based on agricultural heritage system.

Education and training for local people should include three parts:

(a) Education about the values of agricultural heritage system. The aim is to cultivate awarenessof the preservation of agricultural heritage system which lets locals know about heritage values and their connotation, especially the intimate connection between their self-interest and heritage conservation. This will prevent shortsightedness and motivate locals to continue with traditional agriculture and carry forward their culture. If the residents can realize the value of historical culture, their sense of pride and cultural self-consciousness will be increased, and villagers will actively conserve their traditional way.

(b) Education about tourism impacts. Generally, the locals may not have enough knowledge to be aware of the environmental and social costs behind the economic benefits brought by tourism development, which can arrive abruptly after the heritage designation and create unexpected disruption and conflict. Appropriate education can offer a vision about tourism which can bring high quality living standards, while at the same time creating an awareness that fewer farmers and more tourists would create an ecological imbalance which could get out of control and destroy the very resource that they all value. On the other side, they should be told that tourism can help preserve heritage, rejuvenate old handicrafts and provide greater economic prosperity of the area.

(c) Training of tourism service skills. These courses should be professional for locals about tourism management, restaurant services, tourism traffic, commodity production, and sales. They can manage tourism problems better by knowing the laws and regulations, including tourism services standards, hygienic standards and common business practices. For example, training in Mandarin and conversational English will greatly improve their communication abilities. During interviews, tourists said most of them are willing to talk to locals, but did experience language barriers in the Hani terrace areas. Locals also can be trained as guides to introduce their hometown to the visitors and talk about its agricultural wisdom, long history and spectacular landscape, rich culture and so on; besides that, young leaders who are educated can be selected from the residents to join the decision-making for tourism management.

Tourists also should be informed clearly before visiting a rural heritage site that local traditional culture should be respected and not disturbed. Under these principles, visitors would been 
couraged to experience folk culture, and especially the festivals which have close relationships with farming seasons.

\subsubsection{Environmental objectives}

Nature resources are the basis of AHST development. All stakeholders should make great efforts to protect the environment and the ecosystem, maintain the harmonious relationship with nature and at the same time, conserve agricultural biodiversity. Specifically, efforts should be made to measure the capacity of the heritage destination, save natural resources and educate the tourists.

(a) Determining the scale of tourism development according to the most appropriate capacity of the heritage site. The biological environment of the agricultural heritage system is highly sensitive and fragile, and vulnerable to the disruption of external activities. The situation has been worsened by climate change which, for example, causes the continuous lowering of water reserves. Hence, traditional agriculture is facing grave resource depletion challenges (Tian et al. 2015). A large number of tourists would negatively affect the resources essential to plant growth if too many visitors trample the heritage area, threatening the sustainable development of the agricultural heritage system and diminishing the quality of the tourist experience. De-marketing, according to Clements, whereby only certain segments of the tourist population are actively targeted, while others are discouraged, is presented as a means of controlling which types will visit a destination. Hence it is possible for an agricultural heritage site to limit overcrowding (Clements 1989).

(b) Protecting the environment through wellequipped water supply and trash disposal systems. As the water crisis intensifies and water quality deteriorates, water shortage has evolved into an evident global environmental resource problem. Water provides a guarantee for a sustainable agriculture system, but as tourists visit heritage sites they consume large quantities of water, which will be a serious threat in the future. Although sanitary sewage can go through natural purification and for family hotels it is not necessary to install sewagetreatment, human and animal feces as well as agricultural organic solid waste should be used in the biogas anaerobic digestion process. All larger hotels should be required to have sewage treatments facilities. The trash disposal system, including dustbins, rubbish transfer stations, and landfill sites ought to be well designed and maintained. Emerging technologies that reclaim resources from wastewater should also be considered. The oxidation pond (stabilization pond) can reduce the ammonia concentration in the stripper effluent. The wastewater can also be treated concurrently with disposal methods such as subsurface wastewater infiltration and constructed wetlands (Massound et al. 2009; Kim et al. 2014).

(c) Educate visitors about ecological environmental protection and eco-tourism knowledge, and about sustaining the traditional eco-friendly wisdom of agriculture activities. They need to be taught to refrain from activities which degrade the local environment and aware of the destination in order to understand the impact they may have on the environment they visited. Environmentally-friendly consumption patterns of tourists should be encouraged, for example, purchasing organic agriculture products as one of the characteristic tourism commodities in all AHST destinations.

\subsubsection{Social objectives}

It can be generalized that the social goal of AHST is to realize an equitable balance within the local community. That means the cohesion of the local community is strengthened and confirmed through tourism-related engagement. Besides that, representatives of the indigenous inhabitants get more experience by learning and managing and the overall image of the community is reinforced. Finally, an internal consistency between tourism and community is formed, which brings about the improvement of infrastructure in rural areas, local heritage conservation and inclusion of traditional agriculture in local initiatives. In other words, AHST and the local community have been integrated. There are some steps to reach the social goals:

(a) The design of infrastructure such as transportation and sanitation should connect construction in the village with tourism infrastructure, so that it satisfies both tourism development and enhances the living standards of the villagers.

(b) A new type of community organization 
should be built based on the integration of locals. These effective organizations, such as a community tourism association, a community development association and a local tourism coordination group can assist locals to participate in the management and supervision of tourism activities, organize people to join tourism services, and protect traditional agriculture and heritage resources. These contributions of local institutions will strengthen people's sense of belonging and community. The negotiation ability of locals will be enhanced when they, with an economic organization representative, talk to tourism companies and governments. Those selected from locals who have more knowledge and experience of tourism practices can promote the whole community when joining tourism operations. If the locals participate in tourism development with a lack of collective organization and powerful restrictions, there will be disorderly competition and a chaotic situation.

(c) Strengthening community identity, cultivating a sense of community, and increasing local people's satisfaction and feelings of belonging. Agricultural heritage sites are usually located in remote regions and used to be closed, and the whole community has a distinctive group consciousness, and a special set of values. After tourism develops, these social cultures which have conserved traditional agriculture should be shared and related information circulated by the media in a way that re-inforce their values.

\subsubsection{Political objectives}

Tourism has often been triggered by political change. The imperative issue is to build up a decision-making mechanism which can endow the rights of all stakeholders to be involved in making decisions, especially to make sure that local people have a voice and have respectful responses from other tourism stakeholders. Policy construction should be improved to guide AHST in a reasonable way and strengthen its support to farmers, while not just focus on large-scale tourism projects:

(a) There should be an advisory institution to ensure the full participation of the community. For example, the locals and tourism companies need meetings to negotiate tourism issues on time; when making decisions about tourism projects, the tourism company can offer the preliminary scheme to the local community and governments to discuss and reflect the position of relevant departments.

(b) An administration and supervision mechanism is necessary in tourism project implementation. The authorities should take heritage conservation as a matter of prime importance by clearly investigating the vulnerable resources, both natural and cultural, involved in tourism development. Then, make sure the tourism destination offers a safe and clean environment for tourist activities. With high information transparency, all the stakeholders can effectively participate in the project supervision.

(c) Erecting and promoting the heritage site and its assets in the AHST image is the life-force of these tourism destinations. The features of AHST production should be highlighted and displayed through introducing traditional agricultural civilization to tourists in a creative way with prominent local characteristics. At the same time, targeting the tourism market with modern communications technology, especially through internet, will increase both transparency and responsibility.

\section{Conclusions}

Given that meanings are critical to determining the appeal of a particular activity among consumers, and the current uncertainty surrounding the meaning of Agricultural Heritage Systems Tourism (AHST), this study assessed stakeholders' preferences for definitional phrases by using content analysis to identify their categorization. Results show that a shared definition of AHST would be same as verbatim "Attracted by traditional agriculture practices, flavorful food, and associated rural culture, visitors have experiences in an agricultural heritage setting within an attractive natural environment, for education, experience and recreational purposes. As a result, local communities should benefit through sharing their heritage with visitors."

Using the definition of AHST and the investigation about perceptions of stakeholders, this research has summarized the characteristics of AHST in four aspects, and has taken the Hani terrace heritage and the Qingtian rice-fish cultural system as examples to explain: 1) synthesis of 
agritourism, cultural heritage tourism, and ecotourism; 2) the annual variation of tourism attractions and activities; 3) the dominant role of artisan farmers; 4) the unique gastronomic experiences of traditional food.

Considering the definition of AHST and its characteristics, especially the problems and benefits reflected by the stakeholders, systematic objectives are offered by this research from economic, environmental, cultural, social and political perspectives to build up the development framework of AHST. Among them, the economic objective is the core one. The local community should be the principal recipient of benefits from tourism development, receiving sustainable income in order to maintain their commitment for farming in a traditional way. Benefit sharing is one of the surest ways to demonstrate that such sites are managed along sustainable lines. Cultural and environmental objectives are both basic in AHST. The main cultural objectives include two dual aspects: one is that locals realize and are proud of heritage values, feel confidence in their survival abilities, and join heritage conservation practices willingly; the other is that visitors can learn about traditional agricultural resources and knowledge, and respect the special features of local culture. The content of natural objectives means all of the stakeholders should make great efforts to protect the environment and the ecosystem, maintain the long-developed harmonious relationship with nature; the social and political objectives are supportive of the whole framework. From the social aspect, AHST aims for internal consistency between tourism and community, which brings about the improvement of infrastructure in rural areas, local heritage conservation, and the inclusion of traditional agriculture in local initiatives. Politically, the imperative issue is to build up a decision-making mechanism, as well as

\section{Reference}

Agnoletti M (2014) Rural landscape, nature conservation and culture: some notes on research trends and management approaches from a (southern) European perspective. Landscape and Urban Planning 126: 66-73. DOI: 10.1016/j. landurbplan.2014.02.012

Bessière J (1998) Local development and heritage: Traditional food and cuisine as tourist attractions in rural areas. an administrative and supervisory mechanism, which can endow the rights of all stakeholders. Besides, the AHST image should be established and promoted, as well as only targeting certain segments of the tourist population to limit overcrowding.

The innovative feature of definition, characteristics and development framework of AHST is its capacity to bridge the gap between theory and practice and a priori assess to the feasibility of AHST as a sustainable adaption strategy. At the same time, it provides a consistent framework to support academic study of tourism activities and highlights the differences between AHST and other types of tourism to allow more focused research on every stakeholder group involved. The research will also increase our understanding of the motivation and expectations that drive AHST development in the world from the perspective of all the stakeholders. By further research on each of the objectives added here to the AHST development framework, we believe that, with a strong emphasis on experiencing ancestral agricultural livelihoods, AHST will become an effective adaptation tool to support agricultural heritage systems conservation in an appropriate and sustainable manner.

\section{Acknowledgments}

The study is supported by Scientific Research Foundation for Youth Scholars, IGSNRR, CAS, entitled "Evaluation on the conservation and development of agricultural heritage systems in China”. The authors are grateful to the help provided by Administration of World Heritage in Honghe Hani and Yi Autonomous Prefecture during the course of investigation.

Sociologia Ruralis 38: 21-34. DOI: 10.1111/1467-9523.00061 Chen BX and Qiu ZM (2013) Green tourism in Japan: opportunities for a GIAHS pilot site. Journal of Resources and Ecology 4(3): 285-292. DOI: 10.5814/j.issn.1674-764x.2013. 03.012

Clements MA (1989) Selecting tourist traffic by demarketing. Tourism Management 10(2): 89-94. DOI: 10.1016/0261-5177 
(89)90048-4

Eduardo G, Bárbara A, Martha B, et al. (2007) Biodiversity conservation, traditional agriculture and ecotourism: Land cover/land use change projections for a natural protected area in the northeastern Yucatan Peninsula, Mexico. Landscape and Urban Planning 83(2-3): 137-153. DOI: 10.1016/j.landurbplan.2007.03.007

Food and Agricultural Organization (FAO) (2008) Globally Important Agricultural Heritage Systems (GIAHS). Available online at: http://www.fao.org/sd/giahs (Accessed on 6 April 2013).

Gilbert DC (1990) Conceptual issues in the meaning of tourism. Progress in tourism, recreation and hospitality management. Belhaven Press, Hants, UK. pp 4-27

Hjalager A (1996) Agricultural diversification into tourism: Evidence of a European community development programme. Tourism Management 17(2): 103-111. DOI: 10.1016/02615177(95)oo113-1

He L, Min QW (2013) The role of muti-functionality of agriculture in sustainable tourism development in Global Important Agricultural Heritage Systems (GIAHS) sites in China. Journal of Resources and Ecology 4(3): 250-257. DOI: 10.5814/j.issn.1674-764x.2013.03.008.

Jansen-Verbeke M, Priestley GK, Russo AP (2008) Cultural Resource for Tourism: Patterns, Processes and Policies. Nova Science Publishers, New York, USA. pp 115-119.

Jansen-Verbeke M, Mckercher B (2013) Reflections on the myth of tourism preserving "traditional" agricultural landscapes. Journal of Resources and Ecology 4(3): 242-249. DOI: 10.5814/j.issn.1674-764x.2013.03.007.

Kausar D, Nishikawa Y (2010) Heritage Tourism in Rural Areas: Challenges for Improving Socio-economic Impacts, Asia Pacific Journal of Tourism Research 15 (2):195-213. DOI: 10.1080/10941661003629995.

Kim M, Lee H, Kim M, et al. (2014) Wastewater retreatment and reuse system for agricultural irrigation in rural villages. Water Science \& Technology 70: 1961-1968. DOI: 10.2166/wst. 2014.430

Lane B (2009) Rural tourism: an overview. The SAGE Handbook of Tourism Studies. Sage Publications, London, UK. pp 354-371.

Long P, Lane B, Gartner WC, et al. (2000) Rural tourism development. Trends in Outdoor Recreation, Leisure and Tourism. CAB International, Wallingford, UK. pp 299-308. DOI: $10.1079 / 9780851994031.0299$

Lu XL, Wu CY, Holly D (2006) Conceptualizing Ecotourism from a distinct criteria approach by using content analysis. Acta Ecologica Sinica 26(4): 1213-1220. (In Chinese)

Marie S (2009) Local participation in cultural landscape maintenance: Lessons from Sweden. Land Use Policy 26: 214223. DOI: 10.1016/j.landusepol.2008.01.005

Massound MA, Tarhini A, Nasr JA (2009) Decentralized approaches to wastewater treatment and management: Applicability in developing countries. Journal of Environmental Management 90: 652-659. DOI: 10.1016/j. jenvman.2008.07.001.

Min QW, Sun YH, Chen SK, et al. (2007) Primary study on the features and development of GIAHS's tourism resources. Economic Geography 27(5): 856-859. (In Chinese)

Pérez E A, Nadal J R (2005) Host community perceptions: A cluster analysis. Annals of Tourism Research 32(4): 925-941. DOI: $10.1016 /$ j.annals.2004.11.004

Phillip S, Hunter C, Blackstock K (2010) A typology for defining agritourism. Tourism Management 31: 754-758.

Ritchie J, Spencer L, O'Connor W (2003) Carrying out qualitative analysis. Qualitative research practice: A guide for social science students and researchers. SAGE Publications, London, UK. pp 219-262.

Rössler M (2005) UNESCO World Heritage Centre Background Document on UNESCO World Heritage Cultural Landscapes. Prepared for the FAO Workshop and Steering Committee Meeting of the GIAHS Project. Available online at: http://www.fao.org/fileadmin/user_upload/giahs/docs/GIA
HS\%20Strategic\%20Framework.pdf (Accessed on 15 December 2013)

Ryan GW, Bernard HR (2000) Data Management and Analysis Methods. In: Handbook of Qualitative Research , 2nd Edition . SAGE Publications, California, USA. pp 23-45.

Saveriades A (2000) Establishing the social tourism carrying capacity for the tourist resorts of the east coast of the Republic of Cyprus. Tourism Management 21(2): 147-156. DOI: 10.1016/So261-5177(99)0o044-8.

Sim R (2009) Food, place and authenticity: local food and the sustainable tourism experience. Journal of sustainable tourism 17(3): 321-336. DOI: 10.1080/09669580802359293

Singletary M (1993) Mass Communication Research: Contemporary Methods and Application. Publisher: Longman Pub Group; Facsimile edition, New York, USA. pp 54-68.

Snape D, Spencer L (2003) The foundations of qualitative research. Qualitative research practice: A guide for social science students and researchers, SAGE Publications, London, UK. pp 1-23.

Sun YH, Min QW, Chen SK (2009) Residents' attitudes towards tourism in a globally important agricultural heritage systems pilot site: a case study in China. Chinese Journal of Population, Resources and Environment 7(1): 37-46. DOI: 10.1080/10042857.2009.10684908

Sun YH, Jansen-Verbeke M, Min QW, et al. (2011) Tourism potential of agricultural heritage systems. Tourism Geographies 13(1): 112-128. DOI: 10.1080/14616688.2010. 516400.

Sun YH, Wang J, Liu MC (2013a) Community perspective to agricultural heritage conservation and tourism development. Journal of Resources and Ecology 4(3): 258-266. DOI: 10.5814/j.issn.1674-764x.2013.03.009

Sun YH, Mary J, Min QW, et al. (2013b) Conserving agricultural heritage systems through tourism exploration of two mountainous communities in China. Journal of Mountain Science 10(6): 962-975. DOI: 10.1007/s11629-013-2632-6

Tang XY, Min QW, Wu Z (2010) An investigation of residents' perception on tourism in Agro-cultural heritage community. Resources Science, 32(6): 1035-1041. (In Chinese).

Tang, XY (2012) Tourism development of communities in agricultural heritage sites. Tourism education press, Beijing, China. pp82-91 (In Chinese)

Telfer DJ, Wall G (1996) Linkage between tourism and food production, Annals of tourism research 23(3): 635-653. DOI: 10.1016/0160-7383(95)00087-9

Tian M, Min QW, Tao H, et al. (2014) Progress and prospects in tourism research on agricultural heritage sites. Journal of Resources and Ecology 5(4): 381-389. DOI: 10.5814/j.issn. 1674-764x.2014.04.014

Tian M, Min QW, Lun F, et al. (2015) Evaluation of Tourism Water Capacity in Agricultural Heritage Sites. Sustainability 7: 15548-15569. DOI: 10.3390/su71115548

Torres R, Momsen J (2004) Challenges and potential for linking tourism and agriculture to achieve pro-poor tourism objectives. Progress in Development Studies 4(4): 294-318. DOI: $10.1191 / 1464993404$ pso92oa

Vafadari K (2012) Rural tourism and preservation of landscapes in Japan: a spotlight on Satoyama in the Noto Peninsula. Journal of Hospitality \& Tourism 10(2): 87-103.

Veeck G, Che D, Veeck A (2006) America's changing farmscape: a study of agriculture tourism in Michigan. The professional geographer 58(3): 235-248. DOI: 10.1111/j.1467-9272.2006. 00565.x

Wang X, Min Q, Wu D, et al. (2006) Tourism research on Globally-important Ingenious Agricultural Heritage Systems (GIAHS)-A case study on traditional rice-fish agriculture of Qingtian. Areal Research and Development 25(5): 63-67. (In Chinese)

World Tourism Organization (UNWTO) (2009) Tourism Highlights. Available online at: http://www.unwto.org/facts/ eng/pdf/highligts/UNWTO_Highlightso9_en_HR. (Accessed on 23 May 2013) 